\title{
Traumatic high flow vertebral-venous fistula presenting with delayed ischemic stroke: endovascular management with detachable coils and Amplatzer Vascular Plugs
}

\author{
Case report
}

\author{
R. Webster Crowley, M.D., ${ }^{1}$ Ricky Medel, M.D., ${ }^{1}$ and Aaron S. Dumont, M.D. ${ }^{1,2}$ \\ Departments of ${ }^{I}$ Neurological Surgery and ${ }^{2}$ Radiology, University of Virginia School of Medicine, \\ Charlottesville, Virginia
}

\begin{abstract}
Penetrating injuries to the neck can result in a number of abnormalities that are of interest to neurosurgeons and interventional neuroradiologists. Gunshot or stab wounds may cause damage to the cervical spinal cord, the adjacent osseous and ligamentous structures, and the peripheral or cranial nerves. In addition, a significant percentage of penetrating wounds to this location result in vascular injury. These may present insidiously or acutely and with a variety of symptoms. The authors present the case of a patient in whom an occipital lobe infarction developed roughly 2 months after the patient was struck in the neck by a bullet. He was found to have a complete transection of the left vertebral artery, with an associated vertebral-venous fistula. The fistula was eventually treated endovascularly with a combination of platinum coils and Amplatzer Vascular Plugs. The management is discussed, with specific emphasis on the technical aspects of the case. (DOI: 10.3171.2008.12.FOCUSO8274)
\end{abstract}

KEY WORDS $•$ arteriovenous fistula $\quad$ endovascular occlusion $\quad$ stroke
vertebral artery injury

$\mathrm{S}$ ignificant arterial injuries are seen in 15-20\% of all penetrating neck wounds. ${ }^{1,2,9}$ Injuries to the VA represent only a small proportion of these extracranial arterial injuries. ${ }^{2}$ When the VA is injured as a result of penetrating trauma, it may result in a number of vascular abnormalities, including AVFs, transections, or pseudoaneurysms. . $, 2,5,6,9$ These abnormalities may clinically manifest in a variety of ways, with a subsequent variety of potential treatment options. We present the case of a patient who, several months after being shot in the cervical spine, presented with signs and symptoms of a stroke ultimately leading to the diagnosis of a high-flow VVF.

\section{Case Report}

History. This 22-year-old previously healthy man originally presented to an outside hospital after sustaining a gunshot wound to his cervical spine. He survived the assault, but the bullet rendered him quadriplegic from the C-6 level down.

\footnotetext{
Abbreviations used in this paper: AVF = arteriovenous fistula; PICA = posterior inferior cerebellar artery; $\mathrm{VA}=$ vertebral artery; $\mathrm{VVF}=$ vertebral-venous fistula.
}

Approximately 2 months after his injury, while at a rehabilitation facility, he experienced a severe headache that persisted for 6 days, with associated dizziness that eventually progressed to syncope. Magnetic resonance imaging revealed an acute left-sided occipital lobe infarction, and subsequent cerebral angiography revealed a transection of his left VA at the level of C-6, with drainage into a large epidural AVF. The patient was therefore transferred to us for emergent treatment.

Examination. Upon arrival to the University of Virginia, the patient was at his postinjury neurological baseline, which included antigravity strength of his deltoids and biceps with no movement below that level. In addition he had developed a subtle right-sided homonymous hemianopsia. Shortly after arrival, he was taken to the neuroangiography suite for treatment of his fistula. The diagnostic portion of the angiogram confirmed complete transection of the left VA at approximately the level of C-6, which ended in a high-flow VVF. The fistula was noted to drain into the cervical musculature and epidural plexus. The segment of the left VA distal to the transection filled into the $V_{2}$ segment via retrograde flow from the right VA, suggesting mild steal. (Fig. 1)

Treatment. Once the AVF was further characterized, the decision was made to sacrifice the VA. The first step 
R. W. Crowley, R. Medel, and A. S. Dumont

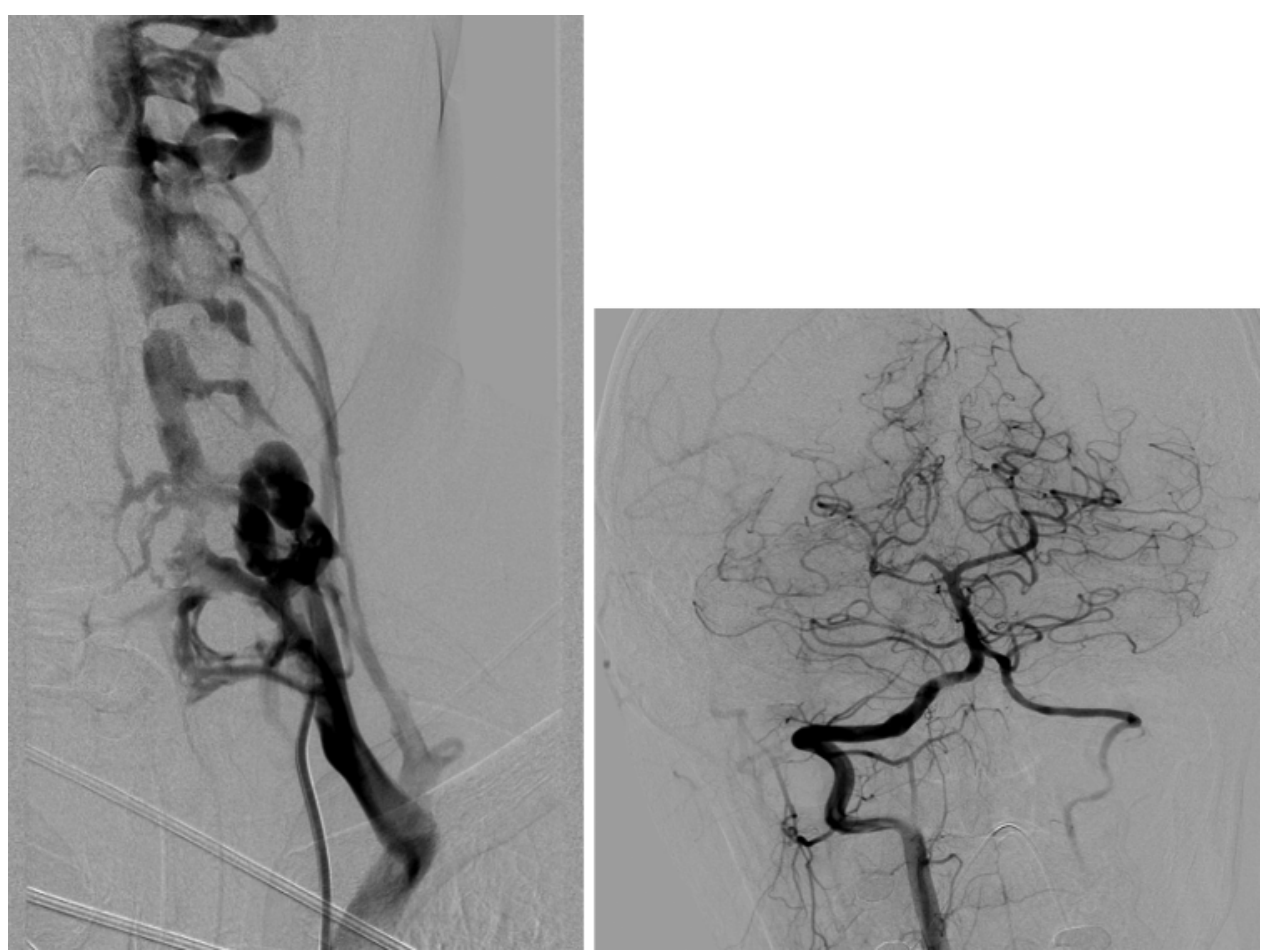

Fig. 1. Pretreatment cerebral angiograms. Left: Anteroposterior (AP) left VA angiogram revealing abrupt transection of the VA at the approximate level of C-6, with high-flow AVF connection with the spinal epidural venous plexus. Rlght: Anteroposterior right VA angiogram demonstrating retrograde arterial flow along the left VA to the distal $V_{2}$ segment.

to achieving adequate exclusion of the lesion was to occlude the distal portion of the left VA. The decision was made to occlude the distal portion prior to the proximal portion to eliminate the possibility of massive intracranial steal after removing the major contribution to the fistula

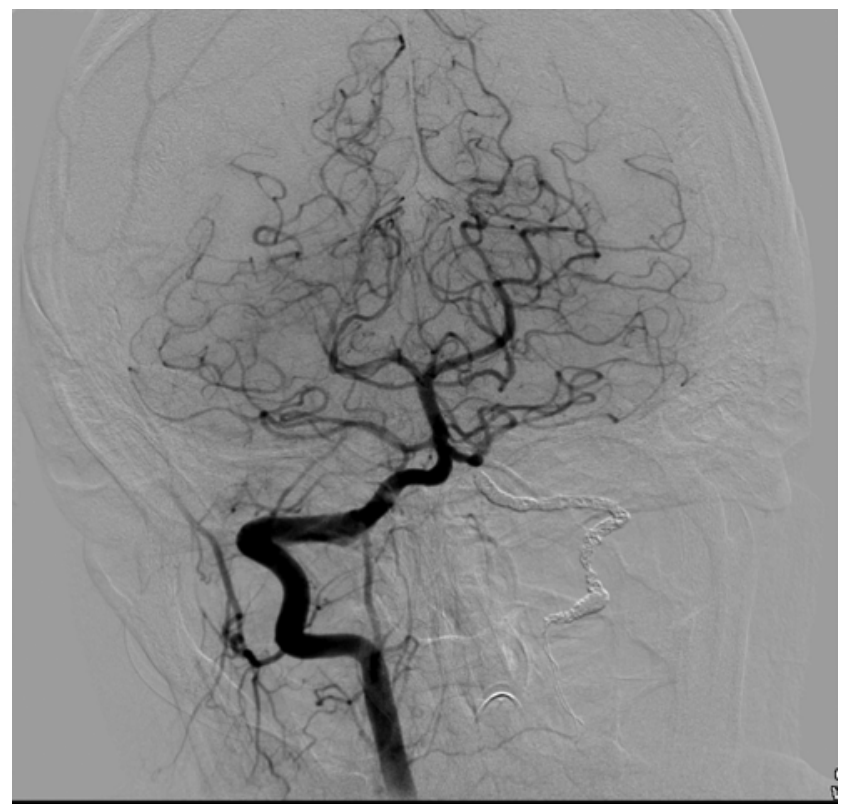

FIG. 2. Posttreatment AP right VA angiogram injection, taken after coil embolization of the distal VA segment. Retrograde flow is present from the right VA to supply blood flow to the left PICA. The VA is obliterated proximal to the origin of the PICA. first. Multiple attempts to catheterize the nondominant left VA from the right were unsuccessful due to difficult geometry. Multiple wire types and curves were tried, but this was ultimately accomplished by placing a J-shaped Excelsior SL-10 (Boston Scientific) microcatheter near the distal left VA via the right VA. This created the appropriate geometry to allow the Transcend-14 (Boston Scientific) microguidewire to select the left VA. The microcatheter was then positioned into the left $\mathrm{V}_{2}$ segment, and the distal VA was occluded using a combination of Hydrocoil (Microvention), Hydrosoft (Microvention), and Axium (ev3 Neurovascular) coils placed from just distal to the transection to just proximal to the origin of the left PICA (Fig. 2). Once the distal portion of the VA was occluded, our attention turned to the proximal vertebral segment with the associated AVF. This was occluded using two 6-mm Amplatzer Vascular Plugs (AGA Medical Corporation) placed immediately proximal to the fistula (Fig. 3). In our case we used a 6 Fr guide catheter to deliver the vascular plugs; however, this can also be accomplished with a 5 Fr guide. The device is a self-expandable nitinol mesh occlusion device with a stainless-steel screw that connects it to a delivery wire, allowing the operator to place it accurately. Once the guide is in the desired location, the device is unsheathed by pulling the guide catheter proximally while stabilizing the wire, expanding the device to its prespecified size. For this reason it is necessary to ensure that the appropriate size implant is chosen. The appropriate size plug is normally 30-50\% larger than the parent vessel. Once the device is deployed, the delivery wire is disconnected from the plug by twist- 


\section{Endovascular treatment of posttraumatic vertebral-venous fistula}

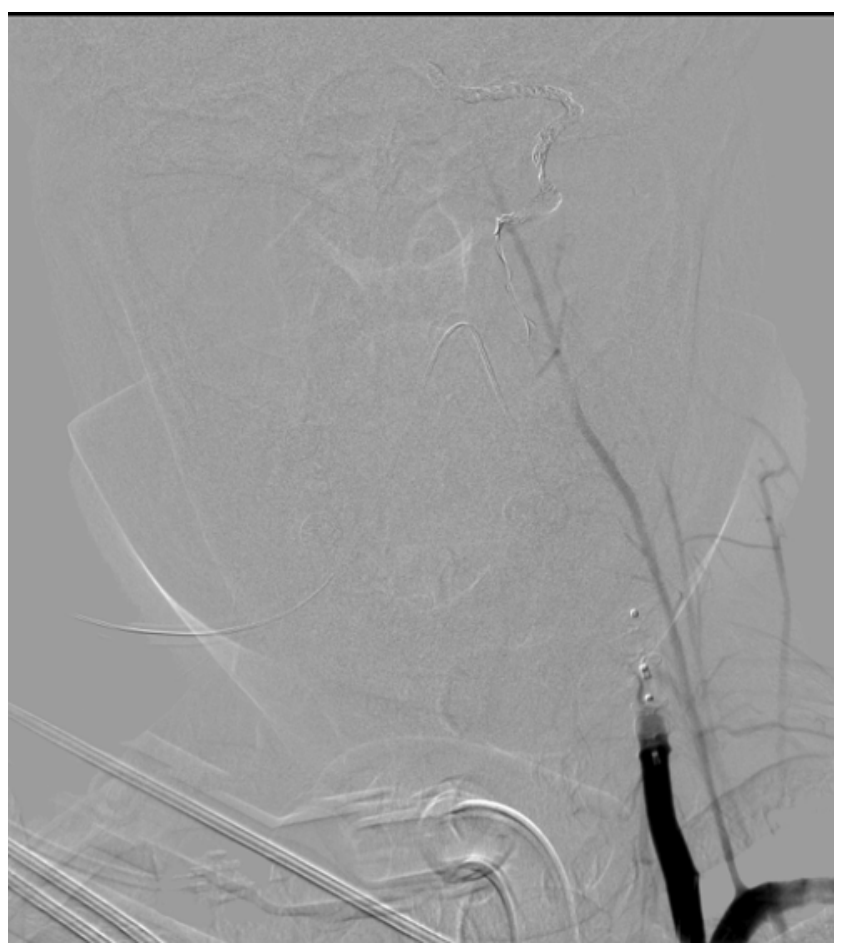

FIG. 3. Posttreatment AP left VA angiogram, taken after placement of the Amplatzer Vascular Plugs, revealing complete obliteration of the proximal left VA segment and the associated AVF.

ing it in a counter-clockwise direction. Figure 4 shows the deployed plugs with the disconnected delivery wire immediately adjacent to the caudal plug.

Posttreatment Course. Postoperative angiograms revealed complete obliteration of the fistula and occlusion of the left VA up to the origin of the PICA. The PICA was noted to fill via retrograde flow from the right VA, and more pronounced anterograde flow was noted through the basilar artery.

The patient remained at his neurological baseline, with no further signs or symptoms of cerebral ischemia. He was placed on aspirin regimen $(325 \mathrm{mg})$ and had an unremarkable postprocedural course.

\section{Discussion}

The patient discussed here presented with signs and symptoms of ischemic stroke secondary to a cervical VA transection. As no vascular injury was noted at the time of the initial assault, it is presumed that a pseudoaneurysm and the fistula formed over the weeks following his injury, followed by complete arterial transection when the pseudoaneurysm ruptured. While it is unclear whether the occipital lobe infarction was due to steal effect down the left VA, or from thromboemboli, it was clear that prevention of future strokes would require left VA sacrifice.

Injuries to the VAs are a rare consequence of penetrating cervical trauma and can be particularly difficult for the treating physician to manage. With trauma such as gunshot or stab injuries, damage to the VA may cause pseudoaneurysms, dissection, occlusion, or AVFs. Al-

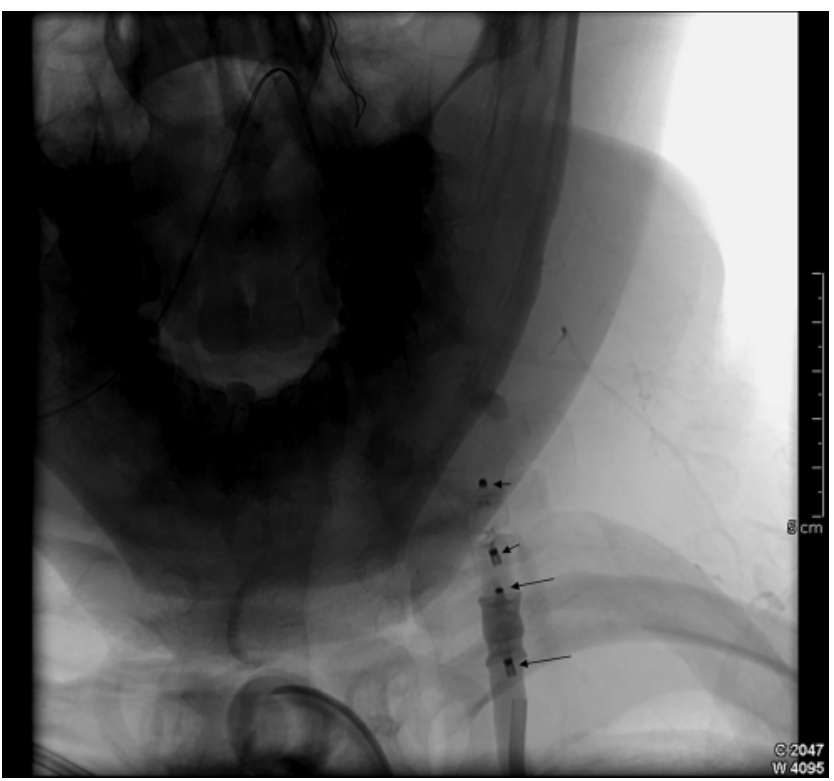

FIG. 4. Unsubtracted AP angiogram demonstrating the placement of the 2 Amplatzer Vascular Plugs. The short arrows point to the distal and proximal marker bands of the rostral plug, signifying the margins of the plug. The long arrows point to the marker bands of the caudal plug. The disconnected delivery wire is seen inferior to the caudal plug.

though pseudoaneurysms or dissections of the VA may be treatable with stent placement, coil embolization, or systemic anticoagulation, the treatment of AVFs such as the one seen in our patient often require sacrifice of the parent artery. Although a large percentage of VVFs present gradually with symptoms such as tinnitus, cervical radiculopathy, or heart failure, high-flow fistulas will often present with more catastrophic symptoms. ${ }^{9}$ These symptoms can include hemorrhage, steal, intracranial venous hypertension, or embolic stroke.

Unlike incidentally discovered AVFs that arguably may not warrant treatment, there is little argument against the treatment of symptomatic high-flow fistulas..$^{1,2,5,6,9}$ Prior to the advent and refinement of endovascular techniques, open surgical treatment was the only option available for such lesions. Typically limited to surgical wrapping or ligation of the parent vessel, open surgery of the extracranial VA is often made more difficult by its location adjacent to osseous structures, including its course within the transverse foramina. However, now that endovascular therapies are becoming more commonplace, these lesions are typically amenable to endovascular treatment, with only the most complex of cases warranting surgical management.

We believe that there are several aspects of this case that warrant further discussion. First, and perhaps foremost, is the order in which the VA segments were occluded. As the proximal VA segment fed the high-flow fistula, it may have seemed intuitive to begin with the occlusion of that segment. However, because the arterial segment distal to the transection was receiving significant retrograde flow from the contralateral VA, we were concerned that eliminating the contribution of the proximal segment to the AVF would result in increased flow from the distal 
segment into the fistula. Because we thought that the patient's ischemic symptoms were likely due to steal effect, we were hesitant to perform any maneuver that would potentially increase the vascular steal down the distal $V_{2}$ segment. We therefore opted to treat the distal segment prior to treating the proximal segment. Although the treatment of the left VA via the right VA can be technically challenging, the use of a preshaped microcatheter enabled us to meet this challenge. There are now torqueable microcatheters, which may also have been useful.

Another technical aspect of this case to emphasize is the use of the Amplatzer Vascular Plug for the occlusion of the proximal VA segment. This plug is an endovascular occlusion device that is often used by vascular surgeons. Recently, however, as detachable balloons have become unavailable in the US, the Amplatzer Vascular Plug has been reported as having potential utility in neurointerventional procedures. . $^{3,8,10-13}$ It provides a relatively costeffective way to occlude parent arteries or abnormal fistulous connections in cases in which a large number of coils might otherwise be required. One potential drawback of the Amplatzer Vascular Plug is the attendant risk of thromboemboli, as it may take up to 30 minutes to completely occlude blood flow, and its porous nature may allow for clots to escape from the plug. ${ }^{3,4,7}$ This was of little concern in this particular case, however, as the proximal VA segment did not contribute to the intracranial circulation, and thus the threat of clinically significant thromboemboli from the proximal VA was nonexistent. Due to its navigability, it was not possible for us to deliver the Amplatzer Vascular Plug across the tortuous vertebrobasilar junction, or we may have used it in the distal vertebral segment as well.

\section{Conclusions}

Penetrating injuries to the extracranial VA rarely occur but can result in various abnormalities. The absence of noticeable irregularities at the initial time of injury does not preclude the eventual formation of such abnormalities. Because of this, the development of focal or nonfocal neurological symptoms in such patients warrants investigation in an expedient fashion. Largely due to innovations in endovascular technology, there currently exists a growing armamentarium of therapeutic options for the treating physician. The Amplatzer Vascular Plug is one such option that may be applied quickly and effectively for the treatment of VA injuries when proximal occlusion is necessary.

\section{Disclaimer}

The authors report no conflict of interest concerning the materials or methods used in this study or the findings specified in this paper.

\section{References}

1. Albuquerque FC, Javedan SP, McDougall CG: Endovascular management of penetrating vertebral artery injuries. J Trauma 53:574-580, 2002

2. Amirjamshidi A, Abbassioun K, Rahmat H: Traumatic aneurysms and arteriovenous fistulas of the extracranial vessels in war injuries. Surg Neurol 53:136-145, 2000

3. Geyik S, Cil BE, Yavuz K, Peynircioglu B, Saatci I, Cekirge S: Neuroapplication of Amplatzer vascular plug: a novel device for parent artery occlusion. Neuroradiology 50:179-183, 2008

4. Gralla J, Schroth G, Kickuth R, El-Koussy M, Do DD, Brekenfeld C: Closing the gap between coil and balloon in the neurointerventional armamentarium? Initial clinical experience with a nitinol vascular occlusion plug. Neuroradiology 50:709-714, 2008

5. Halbach VV, Higashida RT, Hieshima GB: Treatment of vertebral arteriovenous fistulas. AJR Am J Roentgenol 150:405412, 1988

6. Higashida RT, Halbach VV, Tsai FY, Norman D, Pribram HF, Mehringer CM, et al: Interventional neurovascular treatment of traumatic carotid and vertebral artery lesions: results in 234 cases. AJR Am J Roentgenol 153:577-582, 1989

7. Hijazi ZM: New device for percutaneous closure of aortopulmonary collaterals. Catheter Cardiovasc Interv 63:482485,2004

8. Hoit DA, Schirmer CM, Malek AM: Use of the Amplatzer vascular plug as an anchoring scaffold for coil-mediated parent vessel occlusion: technical case report. Neurosurgery 59 (1 Suppl):ONSE171-ONSE 172, 2006

9. O'Shaughnessy BA, Bendok BR, Parkinson RJ, Shaibani A, Batjer HH: Transarterial coil embolization of a high-flow vertebrojugular fistula due to penetrating craniocervical trauma: case report. Surg Neurol 64:335-340, 2005

10. Ratnam LA, Walkden RM, Munneke GJ, Morgan RA, Belli AM: The Amplatzer vascular plug for large vessel occlusion in the endovascular management of aneurysms. Eur Radiol 18:2006-2012, 2008

11. Ross IB, Buciuc R: The vascular plug: a new device for parent artery occlusion. AJNR Am J Neuroradiol 28:385-386, 2007

12. Schirmer CM, Hoit DA, Malek AM: Amplatzer-onyx sandwich: a method for impermeable proximal cerebral vessel occlusion. J Vasc Interv Radiol 19:459-460, 2008

13. Scott DA, Keston P, White P, Sellar R: Vascular plug for ICA occlusion in cavernous carotid aneurysms: technical note. Neuroradiology 50:795-798, 2008

\footnotetext{
Manuscript submitted November 14, 2008.

Accepted December 9, 2008.

Address correspondence to: Aaron S. Dumont, M.D., Department of Neurological Surgery, Box 800212, University of Virginia Health System, Charlottesville, Virginia 22908. email: asd2f@ virginia.edu.
} 